\title{
English language teaching professionals' trajectories within the context of learning organisations
}

\author{
BEATRIX PRICE*
}

Department of English Language Pedagogy, Eötvös Loránd University, Rákóczi út 5, Budapest, 1088, Hungary

\section{THEMATIC ARTICLE}

Published online: June 22, 2020

(c) 2020 The Author(s)

\begin{abstract}
English as a foreign language teachers' associations (henceforth ELTAs) act as empowering platforms for English Language Teaching (ELT) professionals (Lamb, 2012), and yet the contributions of ELTA leaders have not been widely investigated in the fields of second language acquisition and language pedagogy. In order to fill this niche, a qualitative interview study explored the professional trajectories of successful teacher trainers. The paper gives an account of the motivation for continuing professional development (CPD) through the turning points in these professionals' early careers. The findings suggest that there are some similarities behind the motivating factors for CPD and the increasing participation in social spheres (Lave \& Wenger, 1991) leads to professional growth. Moving from the periphery towards the centre in a Community of Practice (CoP) the participants of CoPs become knowledge providers. The results reveal that after members have reached their own plateau and can no longer grow professionally in a particular CoP, they either move on to a different, often more challenging $\mathrm{CoP}$ and often belong to different CoPs and even end up as the leaders of ELTAs. Limitations and further research suggestions are included at the end of the paper.
\end{abstract}

\section{KEYWORDS}

language teacher motivation, continuing professional development, communities of practice, ELT, language teachers' associations

\footnotetext{
*Corresponding author. E-mail: pricebeatrix@gmail.com
} 


\section{INTRODUCTION}

The impact of English as a foreign language teachers' associations (ELTAs) on their members has been proven as having a positive impact (Gnawali, 2016) and leading to professional enhancement; however, studies on the motivation of ELTAs' leaders have been scarce (King, 2018; Paran, 2016). The aim of the current article is to present the results of a qualitative inquiry that explored the driving force of highly motivated English Language Teaching professionals (ELTPs) for professional development in the context of ELTAs, the inter-relationship between the participants' continuing professional development (CPD) and advancement in ELTAs. First, the study explored the professional trajectories of teacher trainers and ELTA leaders and identified similar patterns in their journeys. Secondly, these teacher trainers, besides pursuing their own professional development, often end up in volunteer positions for the professional organisations they belong to. It is a genuine question why these English as a Foreign Language (EFL) teachers devote their time and energy to their professional communities. What is the motivation behind their action? The contextual platform of CPD is oftentimes situated in learning organisations and different Community of Practices (CoPs). The way in which CPD activities are of mutual benefit for both parties is clarified in the research procedure. In order to find answers to these questions and contribute to Second language (L2) teacher motivation research, 16 long, in-depth semi-structured qualitative interviews were carried out with successful teachers and teacher trainers on an international level. Data collection took place at international conferences or via Skype over two years. The participants were asked to reflect on their careers, their sense of achievement and their relationship to their learning organisations. After sketching the theoretical background of EFL teachers' motivation for CPD, the contingent path theory and the contextual description of the setting with CoPs and learning organisations, an overview of the research methods follow. Finally, the emerging themes and results are discussed in detail and a conclusion is presented.

\section{THEORETICAL BACKGROUND}

The literature review is divided into three parts. First, it provides a general overview of L2 teacher motivation and the contingent path theory (Raynor, 1974). In the second part CPD is discussed, and the third part gives a brief description of ELTAs as professional learning communities with Wenger's (1998) indispensable elements of CoPs. These seemingly unrelated constructs are essential to understanding the trajectories of the research participants in their professional organisations.

\section{Language teacher motivation}

Dörnyei and Ushioda (2011) establish four featured components of teacher motivation: 1) prominent intrinsic motivation; 2) social contextual influences relating to external conditions and constraints; 3) temporal dimension with emphasis on lifelong commitment; and 4) demotivating factors, which might result in burnout or demotivation. Pennington (1995) researched L2 teacher motivation with the members of TESOL (Teachers of English to Speakers of Other Languages), the world's largest international association of L2 teachers through the perspective of job satisfaction. She concludes that English as a Second Language (ESL) teachers 
derived greater satisfaction from internal rewards than from external rewards and are intrinsically well satisfied with teaching, but extrinsically dissatisfied with pay, job security and promotion. de Jesus and Lens (2005) propose an integrated model of teacher motivation with several variables: professional engagement, goal value, success expectancies, intrinsic motivation, efficacy expectancy, control expectancy, and success and failure attributions. Hiver, Kim, and Kim (2018) claim that "intrinsic factors relate to satisfaction of needs and interests, emotional payoffs and the internal desire for personal growth, intellectual fulfilment and meaningfulness often found in educational settings" (p.10). Well-being, enthusiasm, positive attitude and other factors contribute positively to teacher motivation (Csikszentmihalyi, 1997; Williams, Mercer, \& Ryan, 2015; Dörnyei \& Kubanyiova, 2014; Szabó, 2016), however, further empirical research is needed to support these claims. Undoubtedly, motivation for professional development is closely related to success, as emphasised in the contingent path theory by Raynor (1974). He argues that "a career is interrelated sets of skill-demanding activities that are engaged in by individuals over time" (p.371) and on the contingent path more and more challenging tasks are performed and successfully delivered and repeated. Thus, achievements support advancement on the career ladder (Pennington, 1995). Although in teacher motivation intrinsic motives are considered more valuable, for example interest in the profession, acquisition of special competence and successful task completion, external drives are just as crucial stimulants in career motivation from the past contingency perspective. External motives can manifest in the form of money, promotion, power, prestige, security, public acclaim, approval of family and friends and so on (Dörnyei \& Ushioda, 2011, p.166). Career context is just as important in teachers' trajectories. For a sustained motivational disposition two crucial factors are necessary: an underlying personal interest on the one hand and the contingent path structure on the other. In case of teachers who cannot develop any further, they reach a final or upper plateau and stay in a closed contingent path but those with reoccurring CPD possibilities advance on an open-ended contingent path. The current study does not cover areas connected to teacher or L2 teacher demotivation or burnout; therefore, it deals only with the latter, the open-ended contingent path. Similarly, Dörnyei and Ushioda (2011) point to the statement by Alexander (2008), "in the literature there is no clear developmental model of teacher motivation that theorises how motives, cognitions, socio-cultural factors and day-to-day practices interact as teachers progress in their professional development". To fill this niche, Maley (2019) collected personal histories of experienced professionals through interpreting Prabhu's (1987) concept, "the teacher's sense of plausibility". By giving an account of building a personal theory of teaching, teacher-specific motivational components are introduced and values, beliefs and experiences reflect on the conceptualization on teacher development. Recent motivational research offers solutions for long-term motivation for L2 language learners in Directed Motivational Currents (Muir \& Dörnyei, 2013) and some investigations have attempted to find L2 teachers' driving forces for teacher development (Mann, 2005). However, there is a lack of enquiry to confirm answers for executives of ELTAs pursuing their strenuous efforts in keeping hundreds of members for a number of years motivated.

\section{Continuing professional development}

Padwad and Dixit (2011) claim that in education there are two distinctive views of CPD, the narrow and the wide views. In the case of the narrow view, teachers acquire some skills or 
knowledge to deal with specific tasks. The wider view considers a much deeper, long-term process with constant development not only on a professional level but on a personal horizon as well and which results in new tasks and challenges. According to them, CPD is

a planned, continuous and lifelong process whereby teachers try to develop their personal and professional qualities, and to improve their knowledge, skills and practice, leading to their empowerment, the improvement of their agency and the development of their organization and their pupils (Padwad \& Dixit, 2011, p. 7).

They separate professional development into two categories, the narrow view of CPD, for instance the in-service short-term courses or one-off workshops, as opposed to the broader view of CPD, which is a long-term process over a longer period of time, which goes deep and results not only in professional but personal growth as well. Generally in literature, continuing professional development is widely used interchangeably with the term professional development or professional growth or even used for teacher development or teacher learning. As Mann (2005) states, these either refer to more institutional or to personal characteristics. According to Illingworth (2016), professional growth opportunities will tap into those interests and strengths in support of helping people reach their next goal as professionals. Maggioli (2004) views effective professional development as a job-embedded commitment, when teachers devote their time for the advancement of the profession while addressing their own particular needs. The connection between language teacher motivation and CPD is an area that can be further exploited to reveal interesting results in motivation research. To fill the research gap, Elsheikh, Coombe, and Effiong (2018) offer a collection of empirical studies in the field, examining both professional development and ELTAs, mainly in the context of TESOL. An autoethnographic reflection (King, 2018) from the volume addresses how volunteering impacts professional development, a pioneering study within the context of ELTAs, reflecting on knowledge, responsibility, skills, attributes, feedback and challenges, mainly on leadership and management development.

\section{English as a foreign language teachers' associations as communities of practice}

ELTAs are communities of practice for those professionals who are engaged in English as a foreign language teaching, teacher training, materials writing, curriculum design and many other areas in connection with ELT.

According to Lamb's (2012, p. 296) definition, ELTAs are "networks of professionals, run by and for professionals, focused mainly on support for members, with knowledge exchange and development as well as representation of members' views as their defining functions". They are supporting networks for professional development and teacher learning (Padwad \& Dixit, 2009). These learning communities are complex organisations, usually with shared knowledge and knowledgeability among people with similar interest or profession. Padwad and Dixit (2014) explore EFL teachers' CPD through smaller units of learning communities, called English Teachers' Clubs. Henri and Pudelko (2003) proposed four types of communities, 1) communities of interest, 2) goal-oriented communities, 3) learner's communities and 4) CoPs. Depending on the strength of a group's social bonds and the extent of intentionality, the level of cohesion among the participants is the strongest in CoPs. Learning in a social context is emphasised in socio-cultural theories (Bandura, 1997), and in social constructivist theories of learning (Vygotsky, 1978), that are in line with the initial construct "situated learning" (Lave \& 
Wenger, 1991), where learning is not just simply absorbing information but increasing participation in social spheres. Later Wenger (1998) developed this idea and described how learning trajectories are formulated by social resources. In a CoP, members are brought together to learn from each other by joining in common activities. Thus Wenger (1998) developed his conceptual framework, the "Social theory of learning", with additional elements of the learning landscapes in the complex systems, where personal growth becomes more emphasised and the trajectory of individuals' participation within the community. As he argues, legitimate peripheral participation gives meaning to learning, where participation is shared and negotiated, participants take different roles, create places for themselves and improve their practices. In a CoP outsiders become members as newcomers, and later move in from the periphery towards the centre, with growing involvement through "centripetal participation" (Lave \& Wenger, 1991, p.100) with the possibility of becoming an expert, as Fig. 1 illustrates.

In order to understand the interconnectedness of the constraints of CoPs, the essential principles need to be listed (Smith, Hayes \& Shea, 2017): a) the domain, an area of knowledge which gives identity to the $\mathrm{CoP}$; b) the community, where members are engaged in doing and learning things together; c) the practice, which refers to the knowledge, methods and documents, everything that is created together; Wenger (2004); d) the participation and reification. Participation is the mutual activity among the members and reification generates artefacts (such as tools, words, symbols, rules, documents, concepts, theories and so on) around which the negotiation of meaning is organised; e) the joint enterprise, mutual engagement and shared repertoire, which means that the members create something together as a valuable resource for common use; f) engagement, imagination and alignment, which are used in CoPs to articulate people's belonging thorough identifying themselves with the image of practice and expressing it through the mission and vision of the community; g) boundaries, which refer to different CoPs that people belong to and cross boundaries; $h$ ) brokering, sharing good practice from one CoP to another, importing and exporting knowledge; i) legitimate peripheral participation, which refers to the trajectories of the newcomers, where through growing involvement they proceed from the periphery towards the centre, gaining more knowledge and gradually sharing more practice with other members of the CoP; j) the identity, which is crucial in viewing ourselves in relation to

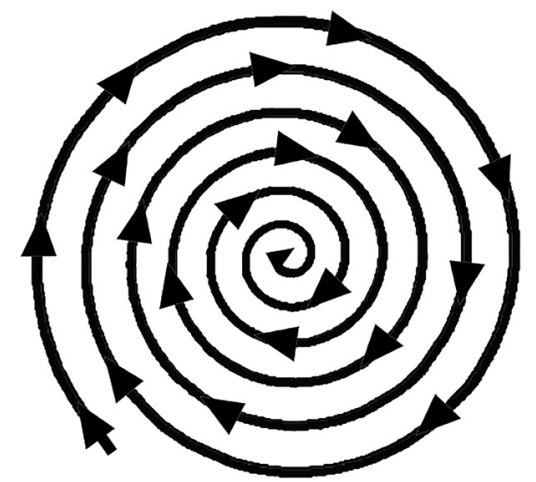

Figure 1. "Legitimate Peripheral Participation" based on Lave and Wenger (1991) 
specific contexts and groups and is a construct of constant change as a result of newly acquired knowledge; h) the knowledge, which is constantly created and shared in the interaction within the $\mathrm{CoP}$, in this way the participants act as both knowledge creators and knowledge generators. Conversely, for a group of people to constitute a CoP, its members must come together around ideas or topics of interest (the domain) and interact with each other to learn together. According to this, national and international ELTAs can be considered as CoPs in a wider sense, whereas their Regional branches (called chapters or caucuses in some countries) or Special Interest Groups (SIGs) are definitely CoPs in the definition's narrowest meaning, as the association members form groups with a particular area of interest. In this sense ELTAs are both knowledge producers and knowledge providers, where members constantly develop their knowledge and develop themselves both personally and professionally. This gives them their identity as a group and distinguishes it from a club of friends or a network of connections between people. This identity is formulated in the associations' mission statements and kept alive through activities that serve their members. Vision is created through building alignment, by reflecting and constructing an image of the practice and by following directions and coordinating actions towards a common goal.

Given all the constraints of CoP listed above, it can be concluded ELTAs are learning communities with a dynamic combination of engagement, imagination and alignment, where value is created through members working together, producing artefacts and formulating a common goal. Conversely, for a group of people to constitute a CoP, its members must come together around ideas or topics of interest (the domain) and interact with each other to learn together. According to this, ELTAs can be considered as CoPs in a wider sense, whereas their SIGs are definitely CoPs in the definition's narrowest meaning, as the association members form groups with a particular area of interest. In this sense ELTAs are both knowledge producers and knowledge providers (Stuart \& Miyahara, 2016), where members constantly develop their knowledge and develop themselves both personally and professionally. This gives them their identity as a group and distinguishes it from a club of friends or a network of connections between people.

\section{METHODS}

\section{Research question}

After reviewing the theoretical background, the inquiry presented in this paper aims to answer the following question:

1. What motivates leading ELT professionals to pursue their continuing professional development and volunteer in professional communities?

\section{Participants}

This qualitative investigation involved 16 (8 male and 8 female) ELT professionals from all around the globe, representing 14 nationalities from 4 continents. Ten of the teachers are NonNative Speakers of English (NNEST) and 6 of them are Native English Speakers (NEST). Eight of them live in their country of origin. They all have extensive teaching experience, more than 25 years each. Apart from International Association of English Language Teachers of English as a 
Foreign Language (IATEFL) or Teachers of English to Speakers of Other Languages (TESOL) International, which most of them are or have been members of, they also belong or used to belong to regional ELTAs and 12 national ELTAs including AINET, ELTAM, ETAI, STIL, IATEFL-Hungary, NELTA, BRAZ-TESOL, TESOL France, URU-TESOL and other language teachers' associations, for instance FIPLV, NATECLA, etc. Additionally, 11 are members of IATEFL SIGs and altogether 10 of the 16 SIGs are represented. In order to correspond to the purpose of the study, as Dörnyei (2007) suggests, the respondents were selected with three main interrelated sampling strategies: a) Criterion sampling; as the selected participants had to meet some specific predetermined criteria, in this case, successful professionals who have become leaders as a result of efficacious professional growth. b) Typical sampling; to show that all interviewees share a common background, which is that they are or have been leaders of professional communities that focus mostly on CPD. c) Homogeneous sampling; where participants are experienced teacher trainers and leading ELT professionals of ELTAs or ELTA-like CoPs. As a result of these purposive sampling strategies, I selected the participants with the principle of maximum variation.

As names carry a lot of connotations and indicate particular kinds of ethnicity, culture, racial belonging and even politico-historical legacy (e.g. colonialism), therefore pseudonyms are eschewed in the present study and simple code numbers are used in the results and discussion section for the participants to be politically, culturally, ethnically and socially neutral. For the same reason to protect the participants' right to anonymity, age and current work place are not mentioned either.

\section{The instrument}

Prior to the main investigation, I conducted a preliminary pilot interview study in the spring term 2017 to find out whether the intended research instrument was good enough quality to answer the content research question and evaluate the instrument's effectiveness. The design, validation and piloting followed McCracken's four-step model (1988), Before piloting the interview, a self-interview was conducted as a preparatory step, then after validation a semistructured interview schedule was finalised. The final interview guide followed a semi-structured format to allow both a certain amount of control and freedom as well. The interviews were planned to enquire over longer periods of the participants' lives and to ask them to reflect on their careers. Apart from general information (background, number of years teaching experience, education) the study was seeking: a) the most important stepping stones on the participants' professional trajectories; b) motivation (to become teachers, motivation to join ELTAs, and motivation for CPD); c) attitudes towards the profession, CPD and ELTAs; d) teaching and voluntary work; e) skills connected to CoPs; and f) vision for the future. The present article focuses on the participants' professional trajectories in connection with the turning points on their professional journeys, in the contexts of CoPs and ELTAs.

\section{Data collection and data analysis}

All the interviews were conducted in English, digitally recorded and stored electronically as sound files, indicating the names, places and times of the interviews. The pilot interviews started in 2017, another seven interviews were recorded the same year and the following year, in 2018; and the remaining nine interviews were administered in 2019. The face-to-face interviews were 
carried out at professional events, mostly conferences in various places, at the IATEFL conferences in Glasgow, Brighton and Liverpool, at the IATEFL Slovenia conference in Terme Topolsica and in Budapest, the researcher's home city and some were managed via Skype. The interviews were transcribed, fine-tuned with the voice recordings, then saved and stored in word documents. The verbatim transcripts yielded a rich database of 90,000-words. Table B1 (Appendix 2) summarises the interview data collected. Data analysis was carried out with the help of the inductive approach, using the constant comparative method (Maykut \& Morehouse, 1994). After the initial analysis of summarizing the most indicative themes from the transcribed data, NVivo12, a qualitative data analysis software, was used to store data segments, use analytical tools and work with data segments. After deriving results from a finalised coding structure, in the process of draughting, redraughting, revising, revisiting and developing the project, having reached saturation, the emerging themes were fine-tuned with the original code manual, secondlevel coding and third-level coding. Table B2 (Appendix 3) summarises the emerging themes of the investigation and for each code brings the most typical example, carefully selected out of the 16 interviews.

\section{RESULTS AND DISCUSSION}

In this section the main emerging themes are be discussed through self-related and contextrelated factors influencing CPD and personal growth. The first part covers the participants' initial studies, as well as guiding influential others as a main motivating influence and a prominent force. The second part portrays CoPs that serve as a nourishing cradle for professional growth, providing a safe environment and giving possibility for knowledge dissemination. In my choice of research methodology I approached motivation for CPD and volunteering in ELTAs from the point of view of the participants' life history. This is the reason I concentrated on life-changing events or crossroads and tried to find similar events among the interviewees that led them towards an engagement in teacher training, organising teacher development events, which enriched both their own professional needs as well as the communities' interests. Having explored the professional trajectories of successful ELTPs in the context of ELTAs through a biographical approach, the main emerging themes are discussed here through selfrelated and context-related factors influencing professional development and personal growth. As a result of this, four distinctive stages were derived that can be seen in Table 1. in thematic grouping. However, due to the length constraints of the paper, only the first two stages are presented in the current article.

\section{Before ELTAs - early influences as a foundation for professional knowledge}

When looking at the different life stories of leading ELT professionals, some similarities immediately sprang up. Interestingly, all the participants have had exposure to different languages, cultures and countries during their life. Most of them have lived in different countries, some of them moved during their childhood, some of them were from immigrant families, while others changed countries during their studies or later in their life for family reasons or for work. \#01 said: 
Table 1 Emerging themes in thematic grouping

\begin{tabular}{|c|c|c|c|}
\hline Before ELTAs & First steps in ELTAs & $\begin{array}{l}\text { Spreading one's } \\
\text { wings in ELTAs }\end{array}$ & Beyond ELTAs \\
\hline $\begin{array}{l}\text { Early influences as a } \\
\text { foundation for CPD }\end{array}$ & $\begin{array}{l}\text { Growing through CPD } \\
\text { in CoPs }\end{array}$ & $\begin{array}{l}\text { ELTAs as formal } \\
\text { providers of CPD }\end{array}$ & Impact on the world \\
\hline Continuing studies & First presentations & Skills & CPD \\
\hline Initial career choice & Voluntary work & Networking & Teachers' wellbeing \\
\hline Countries and cultures & $\begin{array}{l}\text { Growing self- } \\
\text { confidence }\end{array}$ & Turning points & $\begin{array}{l}\text { The ripple effect of } \\
\text { initiatives }\end{array}$ \\
\hline Influential others & LPP in CoPs & Leadership positions & Further steps \\
\hline Scholarships & Like-minded people & Benefits & Value creation \\
\hline
\end{tabular}

"I was born in Argentina. But when I was a year old, my parents took me to Brazil. I was brought up in Brazil but when I was 15 years old, I lived for three months in the United States as an exchange student. And more recently I lived for three years in Canada."

\#10 lists some of the places she lived in:

"I taught in Brazil for 10 years, later in Japan and now for the last 15 years I've been teaching at a further education college in London. The most interesting things I've been doing are the things outside work in the last few years like going to refugee camps in Greece and in Calais to train the teachers there. Since then going to Pakistan, to the SPELT travelling conference all around the country and then more recently going to Africa to help and support."

Evidently the participants have been exposed to many different languages as well as to different cultures. In many cases scholarships from the British Council, Fulbright or the Hornby Trust were sudden turning points in the life of the participants, with enhanced professional development and increased skills. Even those who did not receive scholarships studied or lived in different countries which opened up a new world for them, making them part of the global ELT community, which were undoubtedly life-changing experiences. One Hornby scholar (\#14) summed it up thus:

"My turning point was Plymouth; the Hornby scholarship and my Master's. And it's also a turning point in ELT. Because until then they did not invite me for any training or to do any research work; I was not invited to be a book writer. But when I came back, within two-three months I was busy, super busy, all Saturdays were filled, with training activities, I was here and I was there and all of a sudden, I became famous."

As a result, all of the participants adjusted to the attitude of professional-social mobility which is part of an ELTP's life style and, not surprisingly, as most of them like people, enjoy communicating and travelling. Another aspect, an education-context related phenomenon, can be traced through the professional trajectories of the participants during their studies. It is interesting to note that although many of them had a different initial career choice, wanting to become lawyers, engineers, doctors, simultaneous interpreters, tourist guides or a literary critic, they finally ended up with the teaching profession through a sudden turn. Many of them recall this moment as a memorable experience, for instance \#09: 
"I was training to be a lawyer, during which time I took up part-time teaching to support myself. It was then I realised that I loved teaching and decided to become a teacher."

Teaching is something that is high value to them, working with people or helping others. Another dimension, referring to teachers, mentors, peers or colleagues is connected to the "significant-others" (Shoaib \& Dörnyei, 2005). These influential others acted as escorting navigation, mentioned either in connection with studies, perseverance and direction in further studies or in the difficult times of being a novice teacher. Mentoring is regularly mentioned as one of the most desirable attributes of teachers, both in their pre-service training and in-service careers (Atay, 2008). These mentors acted as role models, as examples to follow. Interestingly, in retrospect, this was often connected to ELT and in many cases they already refer to one of the topics of the next section, becoming members of ELTAs or any other, smaller professional communities. Additionally, some of the studies and scholarships already had influence from IATEFL / Hornby / British Council (\#09, \#12, \#14, \#15), which might have been dormant at the time for the participants, nevertheless, looking back retrospectively, may have had a major role in the forthcoming years.

\section{First steps in ELTAs - growing through CPD in CoPs}

As mentioned in the previous section, there were "influential others" who had an impact on the advancement of the studies of the participants, or in the professionals' career choices. The role of "influential others" played a central part in many of the histories as well as when looking for CPD opportunities and discovering ELTAs. However, some of the ELTPs (\#05, $\# 08$ ) found CoPs due to their intrinsic drive for CPD, either online or by accident, and then attended events, but most of the ELTPs recalled a "guiding hand" who directed them towards some forms of professional communities of ELTAs, either to a special intrest group (SIG) or a regional branch, in some cases to teacher training workshops (\#07, \#10) or immediately to conferences (\#01, \#09, \#11, \#12, \#13, \#14, \#15). Occasionally, members got involved by invitation or awards. \#16 described how she became a member of international IATEFL:

"After my CELTA course I became enthusiastic or even obsessed about new teaching methods, so I started going to a lot of IATEFL events and conferences and because I was interested in professional development, it turned out that I had attended the highest number of events during the year in my ELTA. At the annual national conference then I received a free one-year membership to international IATEFL from then president, Herbert Puchta." (\#16)

\#11 saw this process in the following way:

"I think it's a good way that people get sucked in by accident. Like I was taken along by OUP (Oxford University Press) in 1982 to promote a funny little book and then you think 'Well, this is quite nice and you come back again without any particular plan and then you start to get sucked into things because there's so much going on. You run a newsletter and then other things happen."

After attending some events, members started presenting, although as \#01 described, this was a gradual process: 
"I first attended many conferences as a participant and then I started presenting workshops at the school where I was teaching in a more protected environment. And then as my confidence grew more and more, then I started presenting and submitting proposals. I probably I had the help of colleagues or my coordinator and while the first time you were accepted to go to a conference, you had this mixture of delight and terror. Because you don't know how it's going to be, yet you feel so good when it works out."

A "mixture of delight and terror" is mentioned, something that many experienced professionals have long forgotten. \#15 invoked the anxiety when he recalled his first presentation:

"The school that I was working with partnered with the national ELTA to do the first convention in the country. My teacher said: "OK, we all have to present". And then I replied: "I've just graduated; I'm just a teacher." She said: "It doesn't matter. Find something." And there I was trembling like a leaf; giving this presentation ..., which I was ... oh, I won't to tell you ... it was just meaningful repetition."

$\# 09$ even referred to the fact how difficult it was to submit a proposal, saying.

"I first struggled to understand what a proposal means and how it needs to be written, tried in vain to search for examples elsewhere and then ended up writing a summary of my paper."

Gradually members experienced success and achievement and this led to the growth of selfconfidence and teachers' self-efficacy (Bandura, 1997).

As we can see, CoPs serve as a nourishing cradle for professional growth, and they also give possibilities for the first leadership positions, on many CoP levels: 1) in small learning communities, 2) regional branches, 3) in SIGs in a national ELTA or 4) on an international platform. A regional event was a turning point for \#05: "I went to the second workshop which was about technology, and then I was thinking at home that maybe I can also share something." \#11 started a SIG in 1986 as a SIG coordinator in international IATEFL, whereas \#16, after being a member of the international Business English Special Interest Group (BESIG) for a few years, got the idea to start a BESIG in her national association, which she has been coordinating ever since. Interestingly, in other cases (\#02, \#07, \#10, \#16) the voluntary position was not accompanied by volition. \#10 ended up as joint coordinator for a SIG, as she remembers: "I didn't want to do it. There wasn't any one to take over from the last coordinator. So I allowed myself to be persuaded." \#16 has been the organiser of a CoP for a number of years, but as she looked back, "Actually I didn't even want to do it for one year. It was a misunderstanding; but they wouldn't have had time to find somebody else." The role of "influential others" played a crucial role again, as we can see in the life story of \#07:

"During my third year of my MA there was a call for applications to join a learning technologies SIG as a committee member. And I didn't want to take part but the colleague of mine encouraged me: "Oh, you know so many things about learning technologies, so you should take part." But I said: "No, I don't have the time to volunteer, I'm sorry." And he convinced me, so I sent in my application and I was elected for the position of treasurer. And this is where it all started because I worked with so many amazing people; whom I knew from the headlines of our profession. And it's amazing when you start working with people whom you admire." 
\#02 also accredited "influential others" who encouraged him in the early stages of his leader position, as he did not possess a very positive leader self-image in the beginning:

"I didn't have too much confidence in myself but the power-brokers had confidence in me and would push me in certain directions to organise activities and then I didn't want to let anybody down, so I did it."

In English as a foreign language teachers' associations as communities of practice Fig. 1 illustrated how participants progress in CoPs; first towards the centre in one CoP, learning new skills and acquiring knowledge. After gaining enough self-confidence they reach a tipping point and they take part in swap shops, presentations, give talks and gradually enter the realm of teacher training. After a while they start to proceed outward, as it can be seen in Fig. 2.

To answer the question why people enrol in volunteer positions, other factors were also considered. While learning communities provided a safe environment for personal and professional growth, other perspectives were also mentioned as the driving force behind volunteering. The answer came from almost all the participants unanimously, for instance as \#02 expressed: "In a single word: people. In my involvement over the last 40 years, it's the people I have met." \#11 phrased it differently: "You do a lot of things because a significant proportion of the population is smart and intelligent and have a wish to work with and for other people." \#05 connected voluntary work to the teaching profession:

"This relates back to the very first question. I've chosen to be a teacher because I like helping people. As a teacher that's our main role. And being involved in a teachers' association is also helping people."

Naturally, conferences were the most commonly cited places as the most essential form of further development. This has already been investigated (Aubrey \& Coombe, 2010; Borg, 2015; Jafri, 2010) and in the interview \#4 recounted this:

"When you go to partner associations' conferences, it's not like you're in a different country or with
people who you don't know; it's just a feeling that you belong. So whenever I go to a partner
conference, it's like I'm home with my people. For me that's the most important part of my
involvement with teachers' associations."

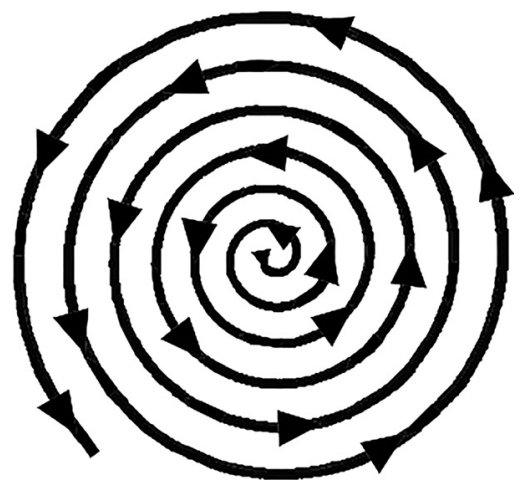

Figure 2. After reaching the centre of $\mathrm{CoP}$ members return to the periphery 
This aspect is strongly connected to Henri and Pudelko's (2003) criteria of CoPs, according to which beside the professional field of interest the members' social bond is just as essential for producing quality work. Based on the aforementioned aspects, it can be confirmed that both successful engagement in professional development and personal factors play a crucial role in members' personal growth. The intrinsic motivation for CPD occurs with a strong social connection within the safety of the supporting networks of CoPs, thus the positive disposition leads the participants towards volunteering in learning organisations. It is connected to the teaching profession, where helping others is a fundamental assumption, and the accompanying satisfaction from accomplishment and positive reward of sharing knowledge with others. This was expressed in Underhill's (2006, p.62) closing article in DALT: "having fun and learning from it as you go, so that you are always having your cake AND eating it." CoPs of ELTAs serve as platform for both personal and professional growth, which is further elaborated in the next section, evaluating the skills learnt in professional communities and the benefits of them in the interviewee's trajectories.

\section{CONCLUSION}

This article investigated the professional development of successful ELT professionals through their careers as teachers, teacher trainers or leaders in ELTAs, in order to identify their motivation for professional growth and taking leadership positions within their associations. The contingent paths of these experts were examined through the lens of legitimate peripheral participation in CoPs (Lave \& Wenger, 1991). From the biographical approach to the participants' life histories four distinctive stages were clearly identified. First, the motivational influences for CPD before ELTA involvement, with a clear progression in studies and interest in professional-cultural mobility. Secondly, the first successful encounter with sharing expertise with colleagues in a protective environment, which often leads to taking on smaller voluntary positions in CoPs. The transitional phases between these stages indicated that success in knowledge transmission and the influence of significant others also played a crucial role for CPD and volunteer positions.

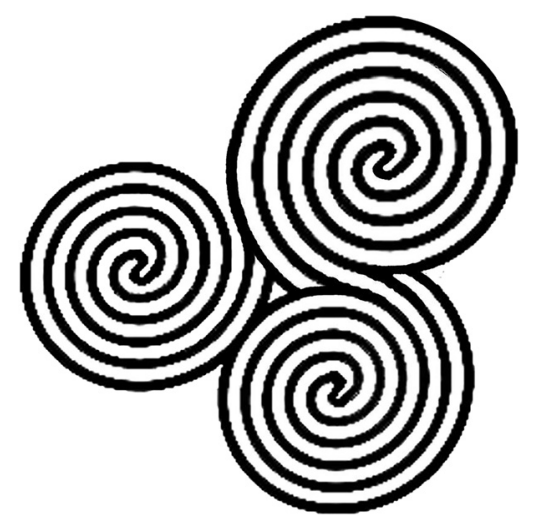

Figure 3. Being members of different CoPs or moving on from one to another 
With respect to personal and professional growth, we have seen that in the beginning, smaller units of ELTAs provide a safe environment for the participants; therefore regional branches, SIGs and local conferences have a significant role for further development. From initially being knowledge consumers, some members of CoPs gradually become knowledge providers (Borg, 2015), moving towards the centre of their CoP with centripetal force. After they have reached their own plateau, some of them can no longer grow professionally and then they may move on to a different, often more challenging CoP, as illustrated in Fig. 3.

Some members when they move on to another sphere and start again from the periphery may end up as the leaders of smaller CoPs. They often belong to multiple CoPs and enrich each of them through cross-boundaries and brokering (Wenger, 1998). Consequently, learning as a social activity takes place through professional development, weaving through the personal histories of career, professional development events and success.

Pedagogical implications can be drawn from the results that smaller units or friendlier CoPs serve as the supporting vessel for personal growth for ELT professionals. As the professional educators move towards the centre of their learning organisations, along the centripetal path of Wenger's legitimate peripheral participation, they gain more professional knowledge, and the motivation they have to share with others and offer it for the benefit of their professional communities grows. To put it simply, learning turns into teaching or training, although it remains an everlasting reciprocal process, in which learning and teaching complement each other continuously. This can be reproduced not only in the context of ELTAs and their smaller learning communities but in any educational institution with continuing professional development at its heart.

Some indications for further research have become apparent. It could be interesting to examine ELTA leaders' long-term motivation for leadership from a temporal point of view (Dörnyei \& Ushioda, 2011), through Wenger's (1998) identity construction or from Dörnyei and Kubanyiova's (2014) vision perspective within the motivational self system. In summary, the outcomes of the present paper highlight the need for ongoing CPD within supportive professional contexts through inner choice for the benefit of all participants in the education scenario.

Ethics: The study procedures were carried out in accordance with the Declaration of Helsinki. Eötvös Loránd University approved the study.

Funding sources: This research received no specific grant from any funding agency in the public, commercial or not-for-profit sectors.

Author's contribution: The author had full access to all data in the study and all references included in this analysis and takes responsibility for the integrity of the data and the accuracy of the data analysis.

Conflict of interest: The author declares no conflict of interest.

\section{ACKNOWLEDGEMENTS}

No additional acknowledgements. 


\section{APPENDICES}

\section{Appendix 1. List of acronyms}

The following list describes the most frequently used acronyms used in the paper:

$\begin{array}{ll}\text { CoP } & \text { Community of Practice } \\ \text { CPD } & \text { Continuing Professional Development } \\ \text { EFL } & \text { English as a Foreign Language } \\ \text { ELT } & \text { English Language Teaching } \\ \text { ELTA } & \text { English Language Teachers' Association } \\ \text { ELTP } & \text { English Language Teaching Professional } \\ \text { ESL } & \text { English as a Second Language }\end{array}$

IATEFL International Association of English Language Teachers of English as a Foreign Language

L2 Second Language

LPP Legitimate Peripheral Participation

NEST Native Speaker Teacher of English

NNEST Non-native Speaker Teacher of English

PD Professional Development

SIG Special Interest Group

TA Teachers' Association

TESOL Teachers of English to Speakers of Other Languages

\section{Appendix 2}

Table B1. Participants and interview data collected

\begin{tabular}{llllllr}
\hline Study & \multicolumn{5}{c}{ Biographical data } & \multicolumn{2}{c}{ Interview } \\
\cline { 2 - 7 } ELTP & Gender & NEST & Region & Place & Date & Duration \\
\hline$\# 01$ & Male & No & Americas & Budapest & 201710 & $0: 44: 18$ \\
$\# 02$ & Male & Yes & Australia & Terme Topolsica & 201803 & $0: 58: 35$ \\
$\# 03$ & Male & Yes & Europe & Brighton & 201804 & $0: 14: 39$ \\
$\# 04$ & Female & No & Europe & Brighton & 201804 & $0: 24: 31$ \\
$\# 05$ & Female & No & Europe & Budapest & 201910 & $0: 47: 30$ \\
$\# 06$ & Female & No & Americas & Budapest & 201804 & $0: 41: 02$ \\
$\# 07$ & Female & No & Europe & Terme Topolsica & 201903 & $0: 18: 48$ \\
$\# 08$ & Female & Yes & Europe & Terme Topolsica & 201903 & $0: 10: 02$ \\
$\# 09$ & Male & No & Asia & Liverpool & 201903 & $0: 54: 58$ \\
$\# 10$ & Female & Yes & Europe & Liverpool & 201903 & $0: 24: 03$ \\
$\# 11$ & Male & Yes & Europe & Liverpool & 201904 & $0: 20: 00$ \\
$\# 12$ & Male & No & Asia & Liverpool & 201904 & $0: 24: 12$ \\
$\# 13$ & Female & No & Americas & Budapest & 201905 & $0: 58: 06$ \\
$\# 14$ & Male & No & Asia & Skype & 201907 & $1: 20: 45$ \\
$\# 15$ & Male & No & Americas & Skype & 201907 & $1: 09: 49$ \\
$\# 16$ & Female & Yes & Europe & Skype & 201911 & $0: 44: 44$ \\
\hline
\end{tabular}




\section{Appendix 3}

Table B2. Emerging themes with examples from the interviews

Before ELTAs
Early influences as a foundation for
CPD

1) Continuing studies

I did my BA in education and then I took an MBA, a Master's in business administration and more recently ... a Master's in education in the area of human development and applied psychology at the University of Toronto. I have also taken millions of courses related to ... alternative education, discipline management and so on. (\#01)

\section{2) Initial career choice}

I was training to be a lawyer, during which time I took up part-time teaching to support myself. It was then I realised that I loved teaching and decided to become a teacher. (\#09)

\section{3) Countries and cultures}

When I moved to London, I worked for the BBC. Later I was doing a lot of volunteering. I taught English in Ethiopia... Then I came back, I spent a couple of years in Europe and then I went to Ecuador. When I retired early from the BBC I went to live in Crete, Greece... (\#13)

\section{4) Influential others}

I have been a leader for many years and I was also named the professional woman of the Year in 2007 in my city. But when they asked me to
First steps in ELTAs

Growing through CPD in CoPs

\section{1) First presentations}

The school that I was working with partnered with the national ELTA to do the first convention in my country. My teacher said: "OK, we all have to present". And then I replied: "I've just graduated; I'm just a teacher." She said: "It doesn't matter. Find something that ..." And there I was trembling like a leaf; giving this presentation ..., which I was ... oh, I won't to tell you ... it was just meaningful repetition. (\#15)

2) Voluntary work

I met the previous organiser of the Creative Café at a conference and I said: "If you're looking for people to do workshops just let me know." And the next thing I knew she misunderstood me. And then a whole bunch of people were saying "Oh, so it's you for the next year." And by that time it was very late. They wouldn't have had time to find somebody else. (\#16)

\section{3) Growing self-confidence}

I didn't have too much confidence in myself when I went on that committee in 1976, but the inspectors and the power-brokers had confidence in me and would push me in certain directions to organise certain activities and then I guess I didn't want to let anybody down, so I did it. (\#02)

\section{4) LPP in CoPs}

I think it's a good way to show how that's working; that people get sucked in by accident or something like I was taken along by OUP to promote a

(continued) 
Table B2. Continued

Before ELTAs
Early influences as a foundation for
CPD

speak in that video last year at the IATEFL conference in Glasgow, I just wanted to run away. I really needed some encouragement to speak there. (\#06)

\section{5) Scholarships}

During my university studies I managed to get a scholarship to go to the United States on my own. It changed my life. ... It was amazing. (\#04)
First steps in ELTAs

Growing through CPD in CoPs

funny little book and then you think: "Well, this is quite nice!", and some nice things go on and you come back again without any particular plan and then you start to get sucked into things because there's so much going on; it's like the SIGs and you run a newsletter and then other things happen. (\#11)

5) Working with like-minded people

I was elected for the position of Treasurer. And this is where it all started because I worked with so many amazing people. People I knew from the headlines of our profession. They were all part of this community. So I started working with them. And it's amazing when you start working with people whom you admire. (\#07)

\section{ABOUT THE AUTHOR}

Beatrix Price works as a teacher and a teacher trainer at the Language Pedagogy Department at the School of English and American Studies, Eötvös Loránd University (ELTE), Budapest. She has extensive experience in teaching children and adult learners. As a teacher trainer, she gives talks, workshops and courses in Hungary and other countries either on Young Learners methodology, using art in ELT, or teacher development. Her interests include holistic education, using art in foreign language teaching, mother-tongue influence on second language acquisition, language teaching methodology, child and teacher development and development of learning organisations.

\section{REFERENCES}

Alexander, P. A. (2008). Charting the course for the teaching profession: The energizing and sustaining role of motivational forces. Learning and Instruction, 18(5), 483-491.

Atay, D. (2008). Teacher research for professional development. ELT Journal, 62(2), 222-224.

Aubrey, J., \& Coombe, C. (2010). The TESOL Arabia conference and its role in the professional development of teachers at institutions of higher education in the United Arab Emirates. Academic Leadership Journal, 8(3), 53.

Bandura, A. (1997). Self-efficacy: The exercise of control. New York, NY: W. H. Freeman. 
Borg, S. (2015). The benefits of attending ELT conferences. ELT Journal, 69(1), 35-46.

Csikszentmihalyi, M. (1997). Intrinsic motivation and effective teaching: A flow analysis. In Bess, J. L. (Ed.), Teaching well and liking it: Motivating faculty to teach effectively (pp. 72-89). Baltimore, MD: Johns Hopkins University Press.

de Jesus, S. N., \& Lens, W. (2005). An integrated model for the study of teacher motivation. Applied Psychology: International Review, 54(1), 119-134.

Dörnyei, Z., \& Kubanyiova, M. (2014). Motivating learners, motivating teachers: Building vision in the Language classroom. Cambridge, UK: Cambridge University Press.

Dörnyei, Z., \& Ushioda, E. (2011). Teaching and researching motivation (2nd ed.). Harlow, UK: Longman. Dörnyei, Z. (2007). Research methods in applied linguistics (1st ed.). Oxford, UK: Oxford University Press. Elsheikh, A., Coombe, C., \& Effiong, O. (2018). The Role of language teachers associations in professional development. Switzerland: Springer.

Gnawali, L. (2016). English language teacher development through teacher associations: The case of NELTA. ELT Journal, 70(2), 170-179.

Henri, F., \& Pudelko, B. (2003). Understanding and analyzing activity and learning in virtual communities. Journal of Computer Assisted Learning, 19, 474-487.

Hiver, P., Kim, T. Y., \& Kim, Y. (2018). Language teacher motivation. In S. Mercer, \& A. Kostoulas (Eds.), Language teacher psychology. UK: Multilingual Matters.

Illingworth, A. (2016). Professional Growth vs. Professional development. Retrieved from https:// professionalgrowth.sweetwaterschools.org/ professional-growth-vs-professional-development/. (Accessed 5 July 2017).

Jafri, N. A. (2010). The impact of continuing professional development on EFL teachers employed in federal universities in the United Arab Emirates. Unpublished doctoral dissertation. United Kingdom: University of Exeter.

King, M. (2018). The impact of LTA volunteerism on leadership and management development: An autoethnographic reflection. In A. Elsheikh, C. Coombe, \& O. Effiong (Eds.), The role of language teachers associations in professional development (pp. 71-86). Switzerland: Springer.

Lamb, T. (2012). Language associations and collaborative support: Language teacher associations as empowering spaces for professional networks. Innovation in Language Learning and Teaching, 6(3), 287-308.

Lave, J., \& Wenger, E. (1991). Situated learning: Legitimate peripheral participation. Cambridge, UK: Cambridge University Press.

Maggioli, D. (2004). Teacher-centered professional development. Alexandria, VA: Association for Supervision and Curriculum Development.

Maley, A. (2019). Developing expertise through experience. UK: British Council Global English.

Mann, S. (2005). The language teacher's development. Language Teaching, 38(3), 103-118.

Maykut, P., \& Morehouse, R. (1994). Beginning qualitative research: A philosophic and practical guide. London, UK: The Falmer Press.

McCracken, G. (1988). The long interview. Newbury Park, CA: SAGE.

Muir, C., \& Dörnyei, Z. (2013). Directed motivational currents: Using vision to create effective motivational pathways. Studies in Second Language Learning and Teaching, 3(3), 357-375.

Padwad, A., \& Dixit, K. (2009). Teacher development in English teachers' clubs (ETCs). English Teaching Professional, Special India and Sri Lanka Edition, 1(1), 34-35.

Padwad, A., \& Dixit, K. (2011). Continuing professional development: An annotated bibliography. New Delhi, India: The British Council. 
Padwad, A., \& Dixit, K. (2014). Exploring continuing professional development: English teachers' clubs in Central India. In T. Wright, \& M. Beaumont (Eds.), Experiences of second language teacher education: Palgrave Macmillan.

Paran, A. (2016). Language teacher associations: Key themes and future directions. ELT Journal, 70(2), 137-149.

Pennington, M. C. (1995). Work satisfaction, motivation and commitment in teaching English as a second language. ERIC Document ED 404850.

Prabhu, N. S. (1987). Second language pedagogy. Oxford, UK: Oxford University Press.

Raynor, J. O. (1974). Motivation and career striving. In J. W. Atkinson, \& J. O. Raynor (Eds.), Motivation and achievement (pp. 369-387). Washington, DC: Winston \& Sons.

Shoaib, A., \& Dörnyei. Z. (2005). Affect in life-long learning: Exploring L2 motivation as a dynamic process. In P. Benson, \& D. Nunan (Eds.), Learners'stories: Difference and diversity in language learning (pp. 22-41). Cambridge, UK: Cambridge University Press.

Smith, S. U., Hayes, S., \& Shea, P. (2017). A critical review of the use of Wenger's Community of Practice (CoP) theoretical framework in online and blended learning research 2000-2014. Online Learning, 21(1), 209-237.

Stuart, A., \& Miyahara, M. (2016). Language teacher associations in Japan: Knowledge producers and/or knowledge disseminators: Researching teacher associations. ELT Journal, 70(2), 137-149.

Szabó F. (2016). The motivational force of employing literature in a foreign language classroom. Hungarian Educational Research Journal, 6(1), 61-70. doi:10.14413/HERJ.2016.04.05.

Underhill, A. (2006). Closing article: Leadership for TAs reps. In Falcão, A., \& Szesztay, M. (Eds.), Developing an association for language teachers. An introductory handbook (3rd ed., pp. 63-68). Canterbury, UK: IATEFL.

Vygotsky, L. S. (1978). Mind in society. The development of higher psychological processes. Cambridge, MA: Harvard University Press.

Wenger, E. (1998). Communities of practice: Learning, meaning and identity. Cambridge, UK: Cambridge University Press.

Wenger, E. (2004). Knowledge management as a doughnut. Ivey Business Journal, 68(3).

Williams, M., Mercer, S., \& Ryan, S. (2015). Exploring psychology in language learning and teaching. Oxford, UK: Oxford University Press.

Open Access statement. This is an open-access article distributed under the terms of the Creative Commons Attribution 4.0 International License (https://creativecommons.org/licenses/by/4.0/), which permits unrestricted use, distribution, and reproduction in any medium, provided the original author and source are credited, a link to the CC License is provided, and changes - if any - are indicated. (SID_1) 